\title{
Study and Development of Inventory Management System for Frozen Food Business in Thailand
}

\author{
Nachayapat Rodprayoon ${ }^{1} \&$ Chuleekorn Chanasit ${ }^{1}$ \\ ${ }^{1}$ Faculty of Business Administration, Rajamangala University of Technology Thanyaburi, Pathum Thani, Thailand \\ Correspondence: Nachayapat Rodprayoon, Information Systems Department, Faculty of Business Administration, \\ Rajamangala University of Technology Thanyaburi, 39 Moo 1, Rangsit-Nakhonnayok Rd. (Klong6), Thanyaburi \\ Pathum Thani, Thailand. Tel: 66-(0) 2549-3241. E-mail: nachayapat_r@rmutt.ac.th
}

Received: February 7, 2019

doi:10.5539/mas.v13n5p70
Accepted: March 15, $2019 \quad$ Online Published: April 30, 2019

URL: https://doi.org/10.5539/mas.v13n5p70

\begin{abstract}
The role of the current business competition in addition to the strategic competition, adjust the marketing model that focuses on reaching the customer exactly. One thing that is no less important than having a concept and adaptation that requires high market flexibility is the business management process. Starting from the process of receiving raw materials to get into the production process, send to the warehouse department to store the products systematically, including deliver the products to consumers promptly. For this reason, many companies around the world have adopted a warehouse management system for predicting, forecasting and checking the status of the products any time. It causes more efficient in internal business process management. At the same time, the type and size of the business cannot apply the same warehouse management system. With different type, size and form of operation process, many companies have an investment situation with an inefficient use of an information system in the organization. It is a wrong decision in applying various systems without considering the related factors. For the study and development of inventory management systems for frozen food business in Thailand, since there are many businesses facing problems of error checking product process, affecting other processes such as raw material forecasting for production, etc. In addition, they are small and medium-sized businesses which their working process managed by the business owner with not many employees. Investment in the use of information systems is therefore a risk in investing and adjusting the form of operations. The result of this research is to analysis the problem and to summarize the requirements for the development of inventory management systems in frozen food business in Thailand in order to respond to the operation process systematically.
\end{abstract}

Keywords: development of inventory management system, inventory system, frozen food business system

\section{Introduction}

\subsection{Introduce the Problem}

The use of information technology in the organization is to help the various work processes faster and efficient, considered as an important thing that leads to large business operations. While the business environment has a relatively high market competition, the number of SMEs in Thailand has increased continuously. (The Office of Small and Medium Enterprise Promotion, 2014) Together with realize the benefits of using information technology to help in the operation for maximizing the resource planning in the organization. (Rasri, 2015) Currently, most SMEs entrepreneurs realize that technology is an important tool to drive business, which helps to communicate and manage all kind of information systematically, including being able to help facilitate and reduce a lot of problems in business operations. (Pfano \& Beharry, 2016) However, it's just a convenient tool, not a guarantee of success or failure at all. Sally Banek has presented a survey of implementing the ERP system in the organization. It was found that there are various factors that affect the implementation of ERP systems in the organization to be successful. Referring to Figure 1, it presents the importance of various factors that needs to ensure the implementation of ERP systems in the organization in order to success in the operation processes as planned. The first three important factors consisting of 1: Management participation. It can be said that the decision to use the system requires support from the management, which is important in driving and acquiring the ERP system. The $2^{\text {nd }}$ factor is doing a business with suitable for their potential considered as the factor of choosing the job to suit the person's or the team's responsible. For the SMEs business, it is a moderate business. The occurrence of errors in the use of the system is minimal. In addition, it is also interesting that small and medium-sized organizations 
turn their attention to technology investments, ERP System. The last factor is the changes in management and communication. If the organization conduct the system to be used in the organization while the communication is not clear. It may cause misunderstandings by employees or system users, and the incorrect use of the system results in a rejection to use the system. Regarding to the above reasons, it can be concluded that the technology is considered a cost of business operation. Most SMEs are able to invest at a certain level. Therefore, the selection of technology must be chosen to match and meet the needs of use as much as possible. (Banek, 2015)

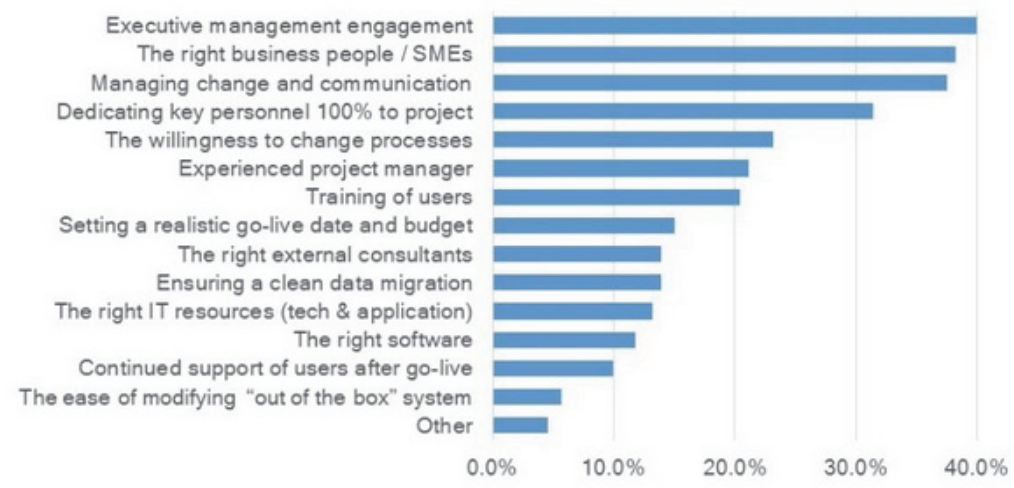

Figure 1. Critical factors for ERP Systems implementation in organization

One of the modules of the enterprise resource planning system is the production management module. Product distribution is a common problem for business management, such as receiving raw materials to get into the production process that cannot be verified and cannot find the products existing, overflow inventory, lacking stock, etc. (Jittham \& Chaovalitwongse, 2017) In this regard, the interesting issues in education and system development in the primary stage emphasized by business operators in Thailand are developing and managing inventory systems to be efficient. (Board of trade of Thailand, 2017) Therefore is the main reason that business operators try to avoid inventory storage for a long time in order to provide efficient inventory management, resulting in using low cost and creating a price advantage. The researcher has collected data and studied the operating process only the importexport frozen food business.

\subsection{Inventory Management System for Frozen Food Business in Thailand}

Thai food processing industry is considered one of the manufacturing industries with high competitiveness in export. In 2015, the overall value of processed food exports in Thailand was 17,322.36 million US Dollars, or equivalent to 3.2 percent of the value of processed food exports worldwide. 34.2 percent of processed food exports are from small and medium-sized businesses. In addition, Thailand is considered the world's $10^{\text {th }}$ largest processed food exporter. The major processed food export market of Thailand is Japan and the United States. (Overall, it is accounting for $29.4 \%$ of the value of processed food export in 2015.) The processed food that Thailand plays an important role at the global level are in both production and export including processed chickens, processed shrimps, and canned pineapples. In addition, the frozen food business has been responding to the new generation continuously and can meet the consumer's need very well. The frozen food has an advantage in shelf life and nowadays consumers accept the standard quality. Furthermore, there are new operators continuously increased in the same direction as the expansion of convenience stores which make frozen food can be easy to buy. Therefore, it causes this type of business accelerate production capacity to meet the needs and tastes of consumers today. As a result, the frozen food market in Thailand continued to grow at an average of 9.8 percent per year. Starting from the year 2011, the market value is at 10,800 million Baht, and until 2015 it is worth 15,700 million Baht. (National Food Institute, 2016) In the market, the inventory system is developed and sold generally. However, the system cannot be used with all types of businesses. Therefore, the development of the system to be suitable for a particular business is an important issue. In addition, the important issue encountered for managing frozen food business in Thailand is related to the inventory management. The small and medium-sized businesses give priority on this matter first, as if it is the center of the production process starting to the process of storing products for delivery to various stores in response to customer needs. (Homsri \& Kongthana, 2014) At the same time, if we study arisen problems and system requirements from business operators. The system will be designed in accordance with the user requirements. Moreover, the system has an operating process model accord with the main process of this type of business in order to develop an inventory management system with particularly suitable for the frozen food 
business.

\section{Method}

This research applies 2 types of tools: questionnaires and in-depth interviews. We use questionnaires to collect data from 50 employees related to the inventory system to study and collect information about the operation process and system requirements, including problems that occur in the past work processes, and various suggestions. In addition, we use in-depth interviews with 10 supervisors or entrepreneurs from 8 companies operating frozen food business to mainly study about the system requirements, operation process, and expectations for administration and management of inventory systems in the future.

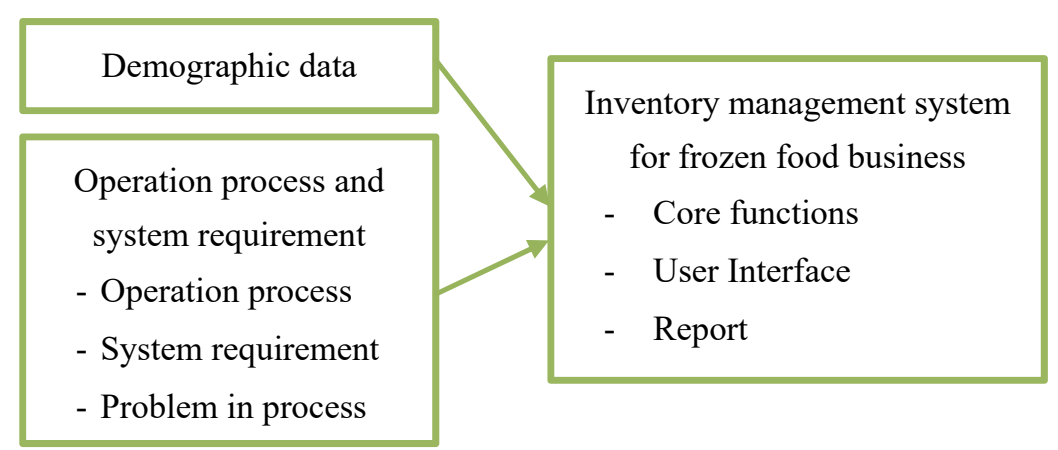

Figure 2. Conceptual Framework

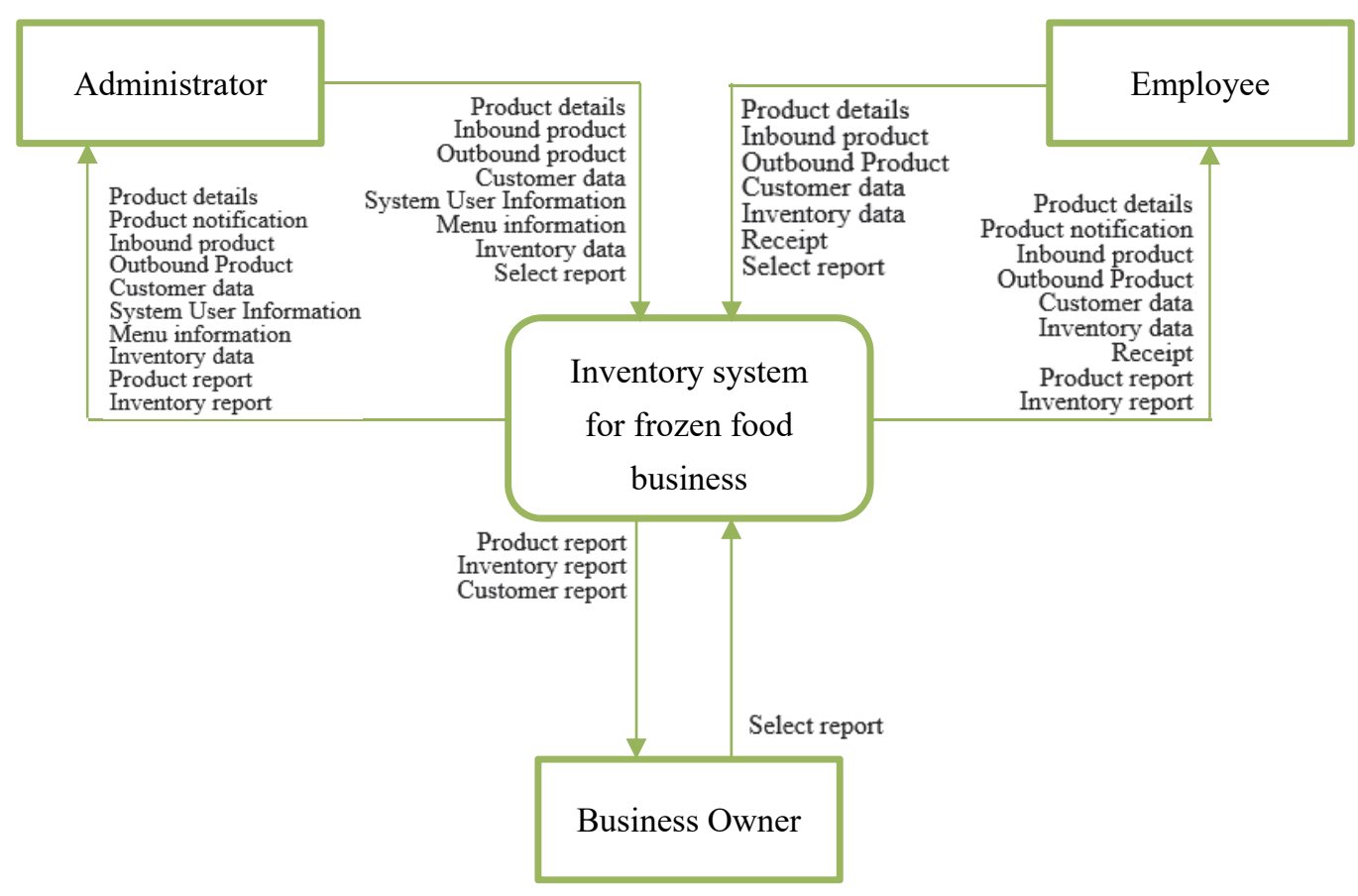

Figure 3. Context Diagram 


\section{Results}

Referring to data from interviewing entrepreneurs and questionnaires from relevant employees, it was found that they want to have a system to manage inventory consisting of the following modules. :

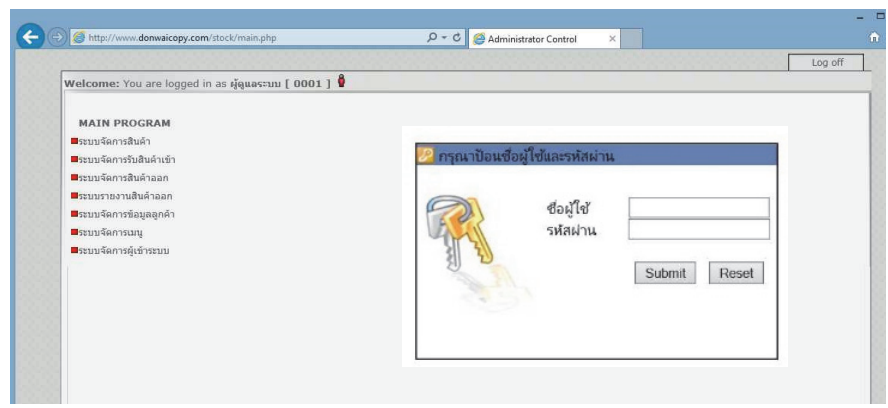

Figure 4. Inventory system for frozen food business

\section{The system is divided into 7 sub-systems as follows.}

Product Management System is used for adding product information into the inventory system in order to know the exactly number of products in the warehouse.

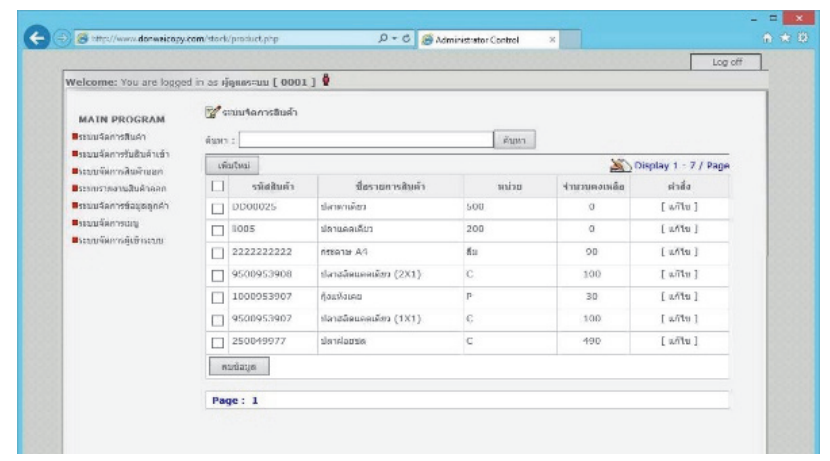

Figure 5. Product Management System

1. Incoming Goods Handling System displays product information into the inventory system, including date of receiving goods into the warehouse, product expiration date, product list, number of incoming goods, and the number of products within the stock in order to allow system users to manage the products in a timely manner. The system users can check the new products from the "Get New Products" command. Then the system will lead users to the "New Product Receiving System" page.

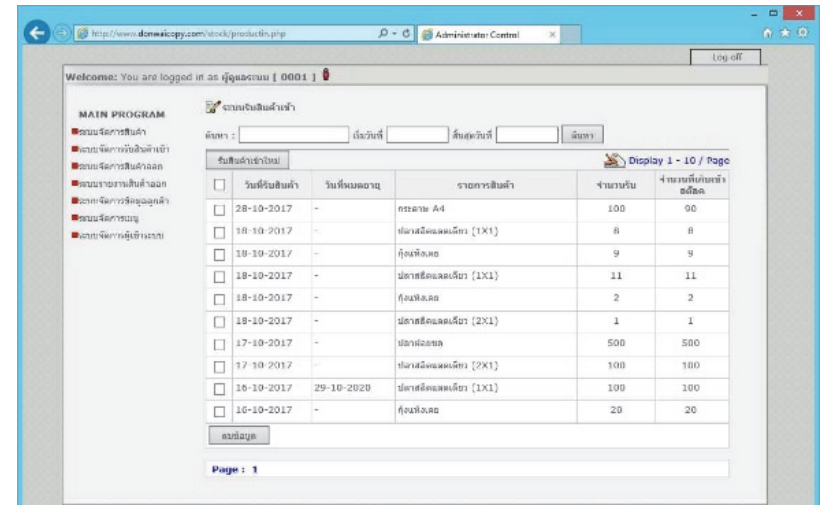

Figure 6. Incoming Goods Handling System

2. Outbound Product Management System displays the list of products, consisting of product codes, product 
names, amount of remaining, selling price, unit price and total product price to withdraw goods from the warehouse. The system users can select the product list below and input the number you want according to the order for the system to calculate and show the result of the total prices.

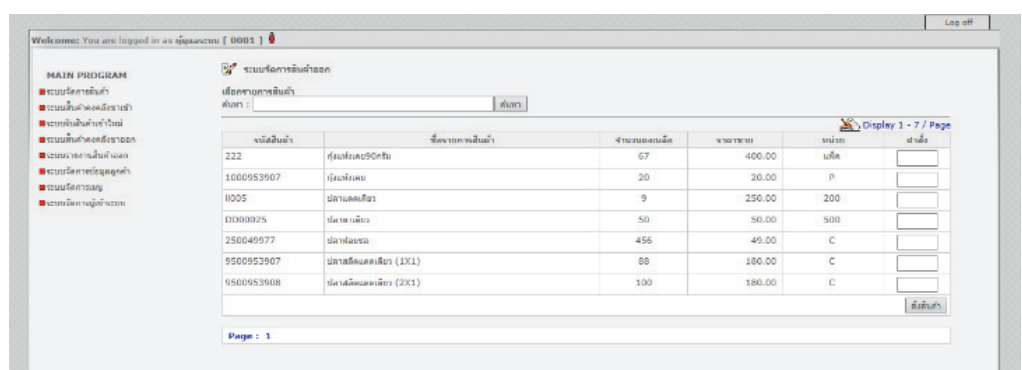

Figure 7. Outbound Product Management System

3. Outbound Product Reporting System is a system to display outbound product information by showing the results from purchase orders of each buyer who ordered and saved various items into the system.

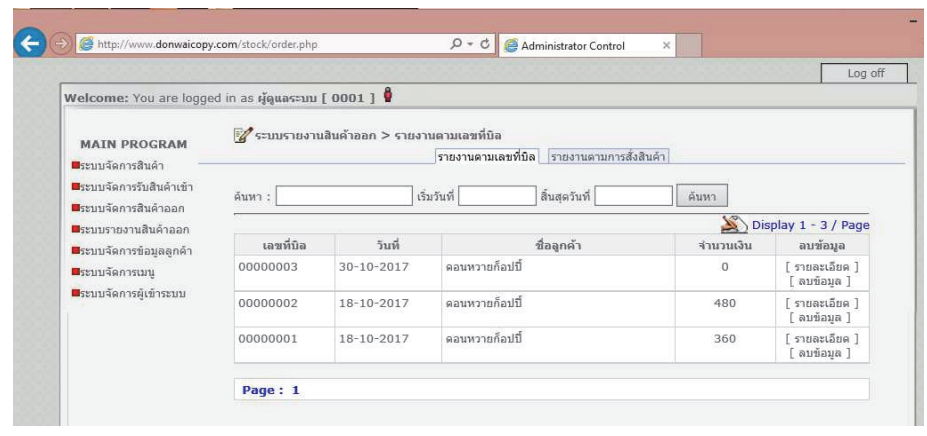

Figure 8. Outbound Product Reporting System

4. Customer Information Management System displays the customer information, customer codes, customer names, phone numbers, and the delivery address to be applied for the next delivery. System users can add information or even update the customer information from the old information as well, by adding information with only press the "Add New" command.

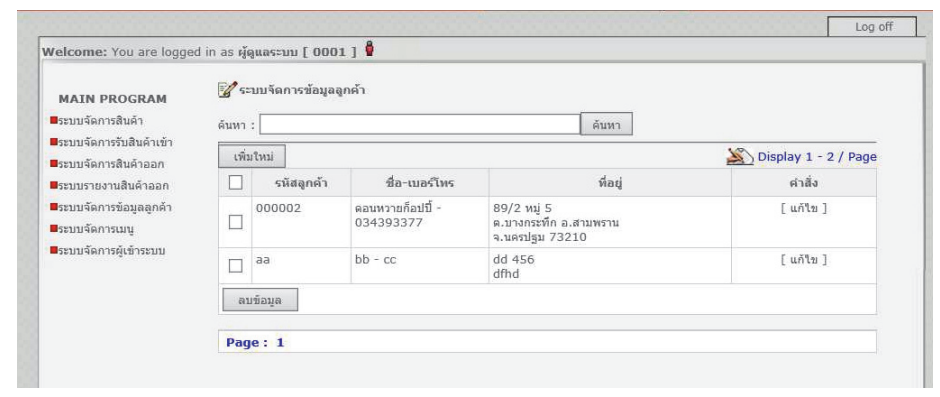

Figure 9. Customer Information Management System

5. Menu Management System displays the command menu instructions within the system by showing the order of the menu. The system users can add a menu bar to save information by pressing the "Add New" button. 


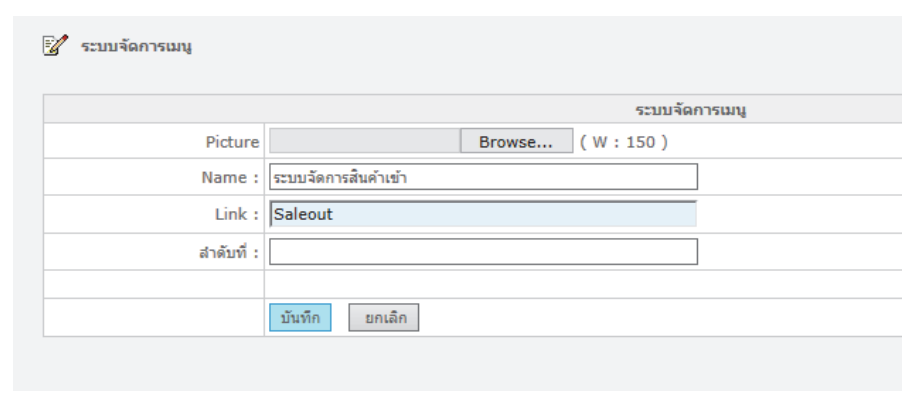

Figure 10. Menu Management System

6. Login Users Management System is for "add data - delete data" of system users in order to determine the system usage rights, and preventing unauthorized access to information. The system divides the level of data usage in the inventory system to be able to manage inventory data. The system administrator can increase the number of users as needed.

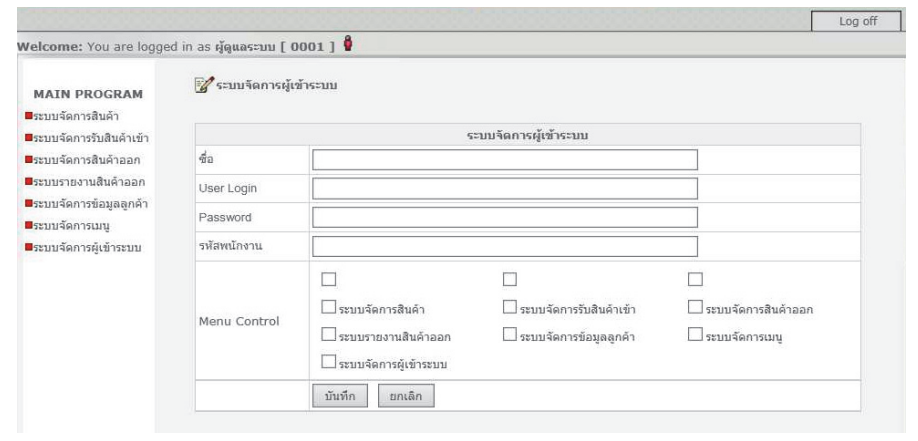

Figure 11. Login Users Management System

For the level of competence about the operation process and the needs of the inventory management system for frozen food business have an overall average at a high level. In term of level of competence about the operation process, respondents commented that entrepreneurs have the ability of administration for most of their tasks in their businesses. Entrepreneurs encourage the use of inventory systems in the organization. There is a plan and change of business plan to suit the continuous changing situation with the highest level of competency. For the entrepreneurs with second level of competence commented that the purchase order and the sales of goods are completed as planned. You understand the operation procedures for your work. There is a risk management to cope with what will happen as always. Your organization has clear management of various tasks. For the ability level at next order and the ability level with less comment which both are at high levels to have a distribution system of the tasks to the responsible person in each section smoothly.

For the level of system requirements, respondents commented that almost all variables are important at the highest level. If we sort out the competency level of system requirement, most of the respondents said that there is an inventory monitoring module in inventory system. It is the first factor to show the system usage requirement. At the same time, the demand for product distribution management system, ordering products and also functions to search for customers and products information. It is considered to order the competence level of system requirements as shown in Table 1 and 2.

Table 1. The level of competency information about the operation process

\begin{tabular}{lccc}
\hline Operational process competency & $\begin{array}{c}\text { Average } \\
(\bar{X})\end{array}$ & $\begin{array}{c}\text { Standard deviation } \\
\text { (S.D.) }\end{array}$ & $\begin{array}{c}\text { Competency } \\
\text { Level }\end{array}$ \\
\hline $\begin{array}{l}\text { Your organization has a clear } \\
\text { management of various tasks. }\end{array}$ & 3.88 & 0.57 & High
\end{tabular}




\begin{tabular}{lccc}
\hline $\begin{array}{l}\text { Entrepreneur is the person who } \\
\text { administer most of tasks in their own } \\
\text { business. }\end{array}$ & 4.54 & 0.64 & Highest \\
\hline $\begin{array}{l}\text { Planning and adjusting the business plan } \\
\text { to suit the continuous changing situation. }\end{array}$ & 4.26 & 0.68 & Highest \\
\hline $\begin{array}{l}\text { There is a risk management to cope with } \\
\text { what will happen as always. }\end{array}$ & 3.97 & 0.63 & High \\
\hline $\begin{array}{l}\text { There is a distribution system of the } \\
\text { tasks to the responsible person in each } \\
\text { section smoothly. }\end{array}$ & 3.72 & 0.57 & High \\
\hline $\begin{array}{l}\text { The purchase order and the sales of } \\
\text { goods are completed as planned. }\end{array}$ & 4.20 & 0.52 & High \\
\hline $\begin{array}{l}\text { Entrepreneurs encourage the use of } \\
\text { inventory systems in the organization. }\end{array}$ & 4.31 & 0.65 & Highest \\
\hline $\begin{array}{l}\text { You understand the operation } \\
\text { procedures for your work. }\end{array}$ & 4.14 & 0.55 & High \\
\hline$\quad$ Overall & 4.15 & 0.60 & High
\end{tabular}

Table 2. Information about the system requirements

\begin{tabular}{llcc}
\hline \multicolumn{1}{c}{ System requirements competency } & $\begin{array}{c}\text { Average } \\
(\bar{X})\end{array}$ & $\begin{array}{c}\text { Standard deviation } \\
\text { (S.D.) }\end{array}$ & $\begin{array}{c}\text { Competency } \\
\text { Level }\end{array}$ \\
\hline $\begin{array}{l}\text { Need a system that helps manage } \\
\text { product sales / purchase orders. }\end{array}$ & 4.76 & 0.42 & Highest \\
\hline $\begin{array}{l}\text { There is an inventory monitoring } \\
\text { module in inventory system. }\end{array}$ & 4.80 & 0.57 & Highest \\
\hline $\begin{array}{l}\text { There is a display screen designed to } \\
\text { be easy to choose from various menus. }\end{array}$ & 4.36 & 0.55 & Highest \\
\hline $\begin{array}{l}\text { There is a license restriction to maintain } \\
\text { data security. }\end{array}$ & 4.08 & 0.47 & High \\
\hline $\begin{array}{l}\text { There are functions to search for } \\
\text { customers and products information. }\end{array}$ & 4.65 & 0.55 & Highest \\
\hline Issue a report for decision making. & 4.26 & 0.63 & Highest \\
\hline $\begin{array}{l}\text { There is a notification in case of the } \\
\text { product is lower than the stock that is } \\
\text { stored. }\end{array}$ & 4.42 & 0.78 & Highest \\
\hline$\quad$ Overall & 4.48 & 0.57 & \\
\hline
\end{tabular}

\section{Discussion}

In terms of inventory system requirements, since the warehouse management process has changed according to the environment and business processes that need to be adjusted to meet the needs of customers continuously. In some factors, the decision to use the inventory system in the organization, if it is a ready-made program, it may be a small investment when compared to the development of the system itself, which may require high capital to build a system to meet the operational processes in their own business. Furthermore, the software package may not match well with the environment and the operational processes of the business. Therefore, the organization needs to study how the system can operate in the organization before deciding to use it, in order to meet the system usage requirements. This is included the skills of the operatives in the organization. The first requirement is a need to apply the inventory management system to the organization in order to be a pilot to the management system and also other departments. Furthermore, it is needed to respond to forecasts and predictions, reduce the risk of 
managing and distributing products to consumers for maximum efficiency. Referring to basic system functions, they want to have a function that can store customer data. In addition to storage the details of the customer, the system must be able to search for customer names, including product management systems that require classifying the types of different products with divergent storage units. The system can be linked to receiving goods in and out to be able to check the issue of disbursement. However, a report is required, in order to reduce the problem of error recordings with not know which operator is the recorder, along with the date and time of recording data. In addition, the system will be alerted if the product is lower than the stock. Lastly, the system can be set the license restriction for easy control of various rights that access to edit or add the related information in the system.

\section{References}

Banek, S. (2015). Recruitment Consultant specializing in the placement of designated accountants, supply chain and IT professionals. Part II - I Survived an ERP Implementation. Survey Results. Retrieved from https://www.linkedin.com/pulse/part-ii-i-survived-erp-implementation-survey-results-sally-banek

Homsri P., \& Kongthana J. (2014). Development of Inventory Management Systems: A Case Study Involving the Installation and Maintenance of Machines for SMEs. Industrial Technology Lampang Rajabhat University Journal, Vol. 7 (pp. 43-44) Lampang, Thailand. Retrieved form https://tcithaijo.org/index.php/Itech/article/download/29215/25400

Jittham S., \& Chaovalitwongse, P. (2017). Inventory Management for Import Frozen Food of Food Services Industry. WMS Journal of Management, Walailak University. Vol.6 (pp. 56-57) Nakhon Si Thammarat, Thailand. Retrieved from https://www.tci-thaijo.org/index.php/wms/article/view/75799/61016

Pfano M., \& Beharry A. (2016). The effect of modern office technology on management performance: Durban Westville. Journal of Problems and Perspectives in Management, 14(2-2), 376-384.

Rasri, S. (2015). Information Technology in Human Resource Management at the Zoological park organization, Bangkok, Thailand. An independent study, Faculty of political science, Thammasat University, Thailand.

The Office of Small \& Medium Enterprise Promotion. (2014). Chapter 6 SMEs High Growth Sectors: Small and Medium Enterprises Situation Report 2014. (pp. 14-21). Bangkok: Thailand. Retrieved from http://www.sme.go.th/upload/mod_downloadA2.pdf

National Food Institute. (2016, April). Frozen food market in Thailand. Retrieved form http://fic.nfi.or.th/MarketOverviewDomesticDetail.php?id=107\#

Board of trade of Thailand. (2017, November 18). SMEs to Thailand to advance to the world 4.0: the 35th National Chamber of Commerce seminar. Retrieved form http://fic.nfi.or.th/MarketOverviewDomesticDetail.php?id=107\#

\section{Copyrights}

Copyright for this article is retained by the author(s), with first publication rights granted to the journal.

This is an open-access article distributed under the terms and conditions of the Creative Commons Attribution license (http://creativecommons.org/licenses/by/4.0/). 